\title{
Quelantes como aditivos anti-hidratação da magnésia
}

\section{(Chelants as magnesia anti-hydration additives)}

\author{
L. F. Amaral, I. R. de Oliveira, R. Salomão, V. C. Pandolfelli \\ Departamento de Engenharia de Materiais, Universidade Federal de S. Carlos \\ Rod. Washington Luiz, km 235, C.P. 676, S. Carlos, SP 13565-905 \\ leaiqsc@yahoo.com.br,vicpando@power.ufscar.br
}

\begin{abstract}
Resumo
A magnésia confere aos concretos excelentes propriedades refratárias aliadas a uma elevada resistência a escórias básicas. Entretanto, na presença de água, ela se hidrata em uma reação expansiva formando o hidróxido de magnésio. A expansão gerada, se não for controlada ou reduzida, danifica a estrutura do material podendo até levar à sua completa desintegração. Neste trabalho, aditivos conhecidos como quelantes foram adicionados à suspensão de sínter de magnésia, com e sem cimento de aluminato de cálcio, a fim de evitar a reação de hidratação da magnésia. Sob o ponto de vista químico, foram realizadas medidas de potencial zeta e grau de hidratação, correlacionando a mudança da carga superficial da magnésia gerada pela presença dos aditivos à quantidade de hidróxido formada. Sob o ponto de vista mecânico e físico, foram realizados o monitoramento da expansão volumétrica aparente e o registro de imagens das amostras. O melhor aditivo anti-hidratação para as amostras com aluminato de cálcio foi o ácido cítrico. A adição de apenas 0,3\%-p foi capaz de quase anular a quantidade de hidróxido formada e adicionalmente zerar a expansão.

Palavras-chave: magnesia, brucita, hidratação, quelantes.
\end{abstract}

\begin{abstract}
Magnesia addition to the refractory castables improves the refractoriness and basic slag corrosion resistance. However, in contact with water, magnesia hydrates by an expansive reaction resulting magnesium hydroxide, $\mathrm{Mg}(\mathrm{OH})_{2}$. If this expansion is not controlled or reduced, it can lead to the rupture and under harsh conditions, to material dusting. In this study, additives known as chelants were added to the magnesia sinter suspensions, with or without calcium aluminate cement, with the objective to inhibit the hydration reaction. Considering the chemical aspects, zeta potential and hydration degree were measured and the changes on the surface charge of magnesia caused by the additives adsorption were correlated to the hydroxide amount generated. Concerning the physical and mechanical aspects, apparent volumetric expansion was recorded. The best additive anti-hydration for the samples containing cement was citric acid. Just 0.3 wt\% was enough to almost inhibit completely the $\mathrm{Mg}(\mathrm{OH})_{2}$ formation, and led to no expansion.
\end{abstract}

Keywords: magnesia, brucite, hydration and chelant.

\section{INTRODUÇÃO}

Concretos refratários contendo magnésia são de grande importância tecnológica por unir as vantagens dos refratários monolíticos às excelentes propriedades do $\mathrm{MgO}$, como elevada resistência à escórias básicas e alta refratariedade $[1,2]$. Além disso, em sistemas $\mathrm{MgO}-\mathrm{Al}_{2} \mathrm{O}_{3}$ é favorecida a formação da estrutura cristalina espinélio, caracterizada por uma elevada resistência ao choque térmico e excelente resistência à corrosão por metais fundidos [3]. No entanto, a magnésia passa por um processo de hidratação rápido e expansivo quando em contato com a água, devido à geração de hidróxido de magnésio, conhecido também por brucita [4]. Essa reação é a principal limitante para a utilização de magnésia em concretos refratários e pode gerar desde o microtrincamento do material até sua completa desintegração. Muitas pesquisas vêm sendo efetuadas visando tanto entender o mecanismo pelo qual a magnésia se hidrata, como desenvolver métodos anti-hidratação. Entretanto, elas apresentam muitas divergências, devido à forte influência de inúmeros fatores sobre a reação de hidratação, tais como: a fonte de magnésia, o seu grau de pureza, a temperatura, o tempo de hidratação e o meio em que a magnésia se encontra. Dessa forma, cada trabalho assume um modelo e se torna difícil adotar um senso comum [5-12]. Mesmo assim, é possível assumir que a hidratação da magnésia ocorre por meio de dois mecanismos distintos, dependendo principalmente da velocidade da reação [13]. Quando a magnésia é mais reativa ou o meio a torna mais susceptível, o mecanismo de hidratação é similar ao da alumina de transição, ou seja, uma hidratação no estado sólido. Já magnésias menos reativas como o sínter de magnésia em temperaturas amenas passam inicialmente por um processo de dissolução seguido pela precipitação da brucita $\left(\mathrm{Mg}(\mathrm{OH})_{2}\right)$, conforme descrito nas reações abaixo [5, 8-10]. 
$\mathrm{H}_{2} \mathrm{O}_{(\mathrm{l})} \rightarrow \mathrm{H}^{+}{ }_{(\mathrm{aq})}+\mathrm{OH}_{(\mathrm{aq})}^{-} \mathrm{K}_{\mathrm{w}}=10^{-14}$

$\mathrm{MgO}+\mathrm{H}_{2} \mathrm{O} \rightarrow \mathrm{MgOH}^{+}+\mathrm{OH}^{-} \rightarrow \mathrm{Mg}^{2+}+2 \mathrm{OH}^{-} \rightarrow \mathrm{Mg}(\mathrm{OH})_{2} \downarrow$

Segundo a equação A, primeiramente ocorre a protonação da superfície da magnésia pelos íons $\mathrm{H}^{+}$provenientes da dissociação da água. Em seguida, os íons $\mathrm{OH}^{-}$aproximamse da superfície carregada positivamente da magnésia dissolvendo os íons $\mathrm{Mg}^{2+}$. Os íons $\mathrm{Mg}^{2+}$ e $\mathrm{OH}^{-}$são gerados até que ocorra a supersaturação da solução e neste momento inicia-se a precipitação do hidróxido. Segundo a reação B, entende-se que a magnésia na presença de água, desenvolve cargas superficiais positivas antes que ocorra a formação de brucita. Dessa forma, a hidratação da magnésia pode ser evitada (ou inibida) pela presença de moléculas que em meio aquoso apresentem espécies negativas e que possam se ancorar na superfície da magnésia carregada positivamente, devido a atração eletrostática entre elas. Tal ancoramento deve gerar uma camada protetora na superfície da magnésia impedindo os íons $\mathrm{OH}^{-}$de se aproximarem para formar o hidróxido. Uma classe de compostos que possui essas características é conhecida como quelantes, moléculas orgânicas que além de ter afinidade por íons metálicos (como o $\mathrm{Mg}^{2+}$ ) ainda apresentam dois ou mais grupamentos negativos capazes de formar estruturas que se assemelham a garras. Essa característica do quelante permite seu ancoramento na superfície da magnésia, conforme esquematizado na Fig. 1. Em pHs básicos, o quelante ácido cítrico perde seus $\mathrm{H}^{+}$ gerando íons citrato ${ }^{3-}, \mathrm{Cit}^{2-} \mathrm{e} \mathrm{Cit}$, os quais serão atraídos para a superfície da magnésia, dificultando o contato da superfície da magnésia com os íons hidroxila $\left(\mathrm{OH}^{-}\right)$do meio aquoso.

Considerando-se esse método de atuação e o mecanismo proposto para a hidratação da magnésia, aditivos que recobrirem melhor a superfície da magnésia, seja pela quantidade de grupamentos negativos, seja pelo melhor arranjo nessa superfície, devem se mostrar mais eficientes contra a hidratação. A fim de verificar essa hipótese, a afinidade de diferentes quelantes pela superfície da magnésia foi avaliada por meio de medidas de potencial zeta, que apontam uma variação nas cargas superficiais do $\mathrm{MgO}$ na presença dos aditivos.

Além do aspecto químico, considerou-se também o

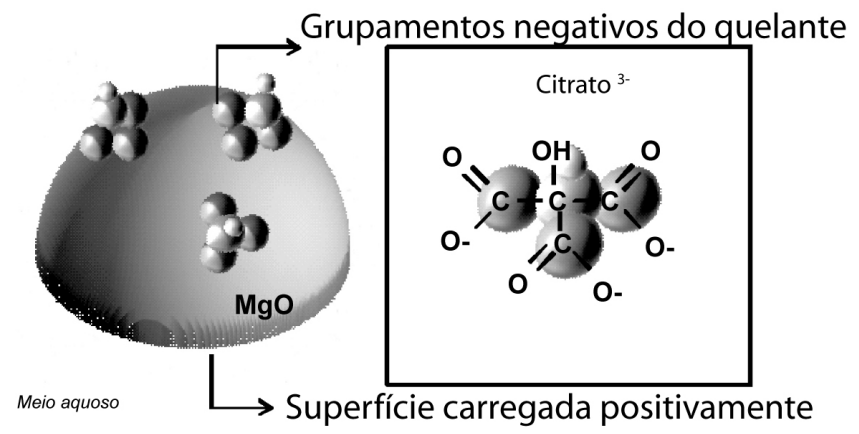

Figura 1: Esquema proposto para o ancoramento do ácido cítrico na superfície da magnésia.

[Figure 1: Proposed diagram for the citric acid adsorption on the magnesia surface.] impacto da presença dos aditivos sobre o aspecto físico e a integridade das amostras, utilizando suspensões mais concentradas. Observou-se que nem sempre um menor grau de hidratação causa um menor efeito deletério e vice-versa. Medidas de expansão volumétrica aparente e o registro de imagens dos corpos de prova foram realizados para avaliar esse aspecto.

\section{MATERIAIS E MÉTODOS}

$\mathrm{O}$ estudo foi realizado utilizando-se sínter magnesiano $\mathrm{D}_{50}<75 \mu \mathrm{m}$, teor $98,2 \%$ p de $\mathrm{MgO}$ e razão $\mathrm{CaO} / \mathrm{SiO}_{2}=2,54$ (Magnesita S.A, Brasil), em duas diferentes concentrações de suspensão.

Suspensões com $12,5 \%$ p de sínter foram utilizadas a fim de obter informações de como a reação ocorre e utilizando técnicas bastante sensíveis de análise, como medidas de potencial zeta, condutividade, $\mathrm{pH}$ e temperatura. A essas suspensões, diferentes quelantes foram adicionados: ácido cítrico (AC), ácido tartárico (AT), citrato de sódio (Cit) e ácido etilenodiaminotetracético, EDTA (ED). A quantidade de aditivo foi calculada baseada na relação aditivo/magnésia utilizada nos demais ensaios, ou seja, $0,3 \%$ p da quantidade de magnésia adicionada. As suspensões foram introduzidas num suporte em banho térmico a $50{ }^{\circ} \mathrm{C}$, e colocadas em contato a um termopar e eletrodos de potencial zeta, $\mathrm{pH}$, condutividade que são acoplados a um computador que coleta os dados gerados no ensaio.

O analisador de potencial zeta (ESA 9800, Matec Applied Sciences) mede a mobilidade das partículas diante de um campo elétrico aplicado e um software à converte no potencial elétrico da partícula no seu plano de cisalhamento (potencial zeta, $\zeta$ ) utilizando propriedades das partículas (como densidade e concentração na suspensão) e do solvente (densidade e constante dielétrica). Portanto, as medidas de potencial zeta indicam a interação da superfície da magnésia com a água e a adsorção de compostos na superfície do $\mathrm{MgO}$ aumenta ou diminui o potencial zeta modificando a mobilidade das partículas [14]. As medidas de condutividade e $\mathrm{pH}$ fornecem, respectivamente, dados referentes às espécies iônicas e à concentração de $\mathrm{OH}^{-}$na suspensão.

Para os demais ensaios, grau de hidratação (G.H.), e expansão volumétrica aparente (EVA), suspensões aquosas concentradas $(67,7 \%$ peso de sólidos) de sínter sem e com $5 \%$ p de cimento de aluminato de cálcio (Secar 71-Kerneos, França) foram homogeneizadas em um misturador de bancada (Ética Equipamentos Científicos S.A., Brasil) durante $2 \mathrm{~min}$. Em seguida, corpos de prova cilíndricos (40 $\mathrm{mm} \times 40 \mathrm{~mm}$ ) e curados por $50{ }^{\circ} \mathrm{C}$ em ambiente saturado numa câmara climatizada Vötsch 2020 durante 7 dias, tempo esse suficiente para a hidratação ser detectada. $O$ grau de hidratação da magnésia foi calculado em um ensaio no qual tais corpos foram pesados depois de secos durante $5 \mathrm{~h}$ a $200{ }^{\circ} \mathrm{C}$ (para garantir a saída de toda água livre presente) e novamente pesados após um tratamento térmico de $5 \mathrm{~h}$ a $800{ }^{\circ} \mathrm{C}$. A diferença de massa entre as duas medidas indica a quantidade de água que foi liberada devido à decomposição 
da brucita, sendo essa quantidade transformada em grau de hidratação utilizando a seguinte equação:

$$
\text { Grau de hidratação }=100 \cdot \frac{\left(\mathrm{M}_{\text {inicial }}-\mathrm{M}_{\text {final }}\right)}{0,45 \cdot \mathrm{M}_{\text {inicial }}}
$$

onde $\mathrm{M}_{\text {inicial }}$ representa a massa após a retirada de água livre e $\mathrm{M}_{\text {final }}$ a massa após o tratamento a $800{ }^{\circ} \mathrm{C}$. A constante inserida na fórmula corresponde à estequiometria da reação e transforma a quantidade percentual de água perdida por quantidade percentual de magnésia reagida. Dessa forma, o grau de hidratação reflete a quantidade de magnésia que reagiu com a água transformando-se em hidróxido. Para as amostras com cimento esse cálculo não pode ser aplicado, pois esse método não permite identificar a perda de água referente aos hidratos e hidróxido isoladamente, ou seja, reflete apenas a perda de água total. Portanto, para as amostras que continham CAC, realizaram-se ensaios de perfil de secagem no qual se registra a massa em função da temperatura da amostra. As decomposições dos hidratos do cimento ocorrem no intervalo de 180 e $350^{\circ} \mathrm{C}$ enquanto, do hidróxido ocorrem entre 350 e $500^{\circ} \mathrm{C}$, permitindo a distinção entre as quantidades formadas dos respectivos compostos. O grau de hidratação da magnésia foi calculado descontandose a quantidade de hidratos de cimento formado $(2,87 \%$ p).

Os danos físicos causados devido à hidratação foram avaliados por meio da medida de expansão volumétrica aparente (EVA). Essa técnica não permite quantificar o grau de hidratação do $\mathrm{MgO}$, mas seus danos podem ser estimados de forma simples, contínua e reprodutível. A técnica utiliza moldes poliméricos cilíndricos não aderentes, com paredes finas e flexíveis capazes de se expandir. A expansão do $\mathrm{MgO}$ deforma o molde e permite que a medida das dimensões seja feita de forma padronizada. Calculando-se a diferença percentual entre os volumes final e inicial, determina-se o valor da EVA em função do tempo. As equações utilizadas foram:

$$
\begin{aligned}
& \mathrm{V}_{\mathrm{i}}\left(\mathrm{mm}^{3}\right)=\left(\frac{\mathrm{H}_{\mathrm{i}} \cdot \pi \cdot(\mathrm{D}-2 \mathrm{t})^{2}}{4}\right) \\
& \operatorname{EVA}(\%)=100 \cdot\left(\frac{\mathrm{V}_{\text {final }}-\mathrm{V}_{\text {inicial }}}{\mathrm{V}_{\text {inicial }}}\right)
\end{aligned}
$$

onde t é a espessura da parede do molde, $\mathrm{V}_{\mathrm{i}}$ é o volume da amostra em um determinado tempo e EVA é o aumento percentual de volume ocorrido. Uma descrição mais detalhada da técnica e exemplos de sua aplicação pode ser encontrada na ref. [1].

\section{RESULTADOS E DISCUSSÃO}

\section{Aspectos químicos}

A hidratação da magnésia na ausência de aditivos

O elevado potencial zeta no inicio do ensaio $\left(\zeta_{\mathrm{i}}\right)$ sugere que a primeira etapa da reação, a protonação da magnésia e a conseqüente liberação de íons $\mathrm{OH}^{-}$para a solução, ocorre assim que o óxido entra em contato com a água Os valores iniciais de condutividade $\left(\mathrm{C}_{\mathrm{i}}\right)$ e $\mathrm{pH}(\mathrm{pH})$ também evidenciam que esta etapa é instantânea, já que a liberação de íons $\mathrm{OH}^{-}$ eleva o pH e a condutividade iniciais da suspensão.

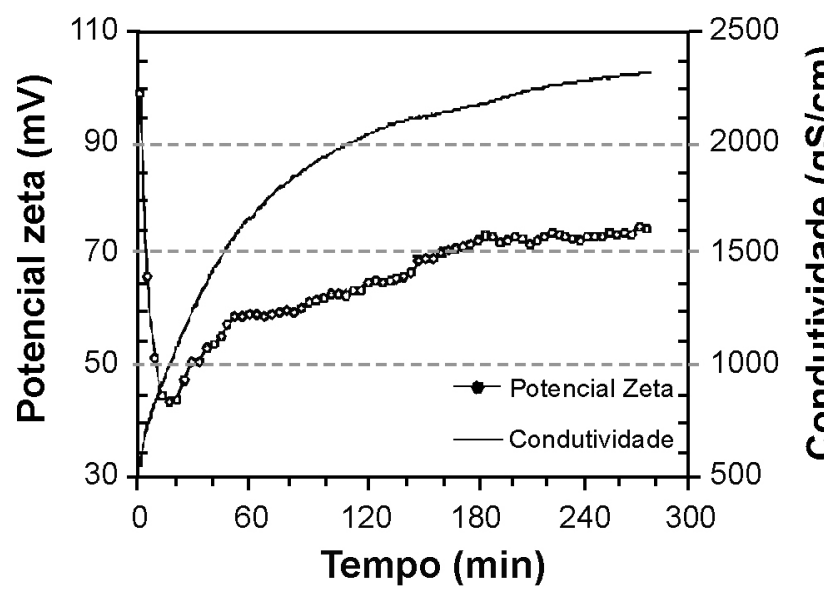

Figura 2: Potencial zeta e condutividade de suspensões aquosas de sínter de magnésia em função do tempo.

[Figure 2: Zeta potential and conductivity with the time for aqueous suspensions containing 12.5 wt\% of magnesia.]

Em seguida, observa-se o início da dissolução, na qual ocorre a aproximação dos íons $\mathrm{OH}^{-}$e a dissolução da magnésia em $\mathrm{Mg}^{2+} \mathrm{e} \mathrm{OH}^{-}$. Essa etapa leva a uma diminuição no potencial zeta das partículas devido à neutralização de cargas pela aproximação dos grupos negativos $\mathrm{OH}^{-}$. Simultaneamente, um aumento no $\mathrm{pH}$ e na condutividade é observado devido a liberação na suspensão de íons $\mathrm{OH}^{-}$ provenientes da dissolução. As curvas de condutividade e $\mathrm{pH}$ mostram que a velocidade de formação de $\mathrm{OH}^{-}$diminui com o decorrer do tempo, sugerindo que as concentrações das espécies $\mathrm{Mg}^{2+} \mathrm{e} \mathrm{OH}$ na suspensão estão se aproximando

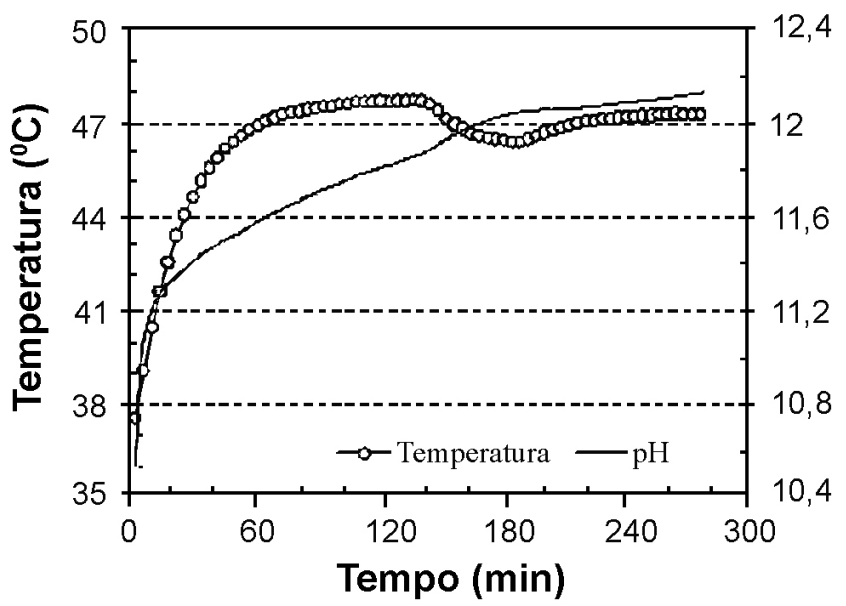

Figura 3: Variação da temperatura e do pH de suspensões aquosas de sínter de magnésia em função do tempo.

[Figure 3: Temperature and $\mathrm{pH}$ with time for aqueous suspensions containing $12.5 \mathrm{wt} \%$ of magnesia.] 
às concentrações de equilíbrio. Entretanto, o óxido de magnésio não é a forma mais estável do sistema $\mathrm{Mg}-\mathrm{H}_{2} \mathrm{O}$, e por isso esse processo tem continuidade e não pára apenas na etapa de dissolução como é o caso por exemplo do $\mathrm{NaCl}$, entre outros sais. Ao supersaturar a suspensão inicia-se a formação de hidróxido de magnésio $\left(\mathrm{Mg}(\mathrm{OH})_{2}\right)$, que é mais estável termodinamicamente que o $\mathrm{MgO}$.

A precipitação de hidróxido, conforme mostra a reação $B$ desloca a reação favorecendo a reprotonação da superfície da magnésia, posteriormente sua dissolução e novamente a precipitação. Esse deslocamento no equilíbrio da reação global A pode ser notado na Fig. 2. Após a estabilização térmica da suspensão com o banho (aproximadamente 70 min. após o início do ensaio) a temperatura permanece constante por um período e em seguida diminui. Essa diminuição ocorre simultaneamente a um aumento no $\mathrm{pH}$, sugerindo que além de ocorrer a redissolução da magnésia (evidenciada pela liberação de íons $\mathrm{OH}^{-}$para o meio aquoso), esse processo é endotérmico, i.e, necessita de energia. Esse sistema de dissolução/precipitação é conhecido como ciclo de Le Chatelier.

Conforme os resultados apresentados, a hidratação da magnésia em água pura nas condições estudadas, ou seja, suspensões de $12,5 \%$ p de sínter de $\mathrm{MgO}$ de pureza $98 \%$ p e em temperaturas amenas (da ordem de $50^{\circ} \mathrm{C}$ ), a precipitação do hidróxido não ocorre de maneira massiva, mas sim em várias etapas dissolução/precipitação, seguindo o ciclo de Le Chatelier.

\section{A hidratação da magnésia na presença dos quelantes}

Antes da adição do $\mathrm{MgO}$, dois equilíbrios químicos de dissociação estão presentes, o de dissociação da água (descrito anteriormente) e o de dissociação dos quelantes, sendo que o último envolve várias constantes de equilíbrio, pois cada quelante apresenta no mínimo dois grupos dissociáveis. Ao adicionar a magnésia nesse sistema ocorrerá a protonação de sua superfície, tanto por íons $\mathrm{H}^{+}$provenientes da dissociação do quelante como por íons $\mathrm{H}^{+}$provenientes da dissociação da água. Em seguida, as espécies negativas se aproximam da superfície da magnésia a fim de solubilizar os íons $\mathrm{Mg}^{2+}$. Neste caso, diferentemente no caso da hidratação em água pura, duas espécies negativas podem se aproximar da superfície da magnésia: i) os íons $\mathrm{OH}^{-}$provenientes da água como no caso da hidratação na ausência de aditivos ou ii) os íons Quel ${ }^{\mathrm{x}-}$ produzidos pela dissociação dos quelantes na água. Quando ocorre essa aproximação, sugere-se duas possíveis rotas para a reação: i) Os íons Quel ${ }^{\mathrm{x}-}$ capturam os íons $\mathrm{Mg}^{2+}$ que foram dissolvidos pelos $\mathrm{OH}^{-}$, segundo as reações:

$$
\begin{aligned}
& \mathrm{MgOH}^{+}+\mathrm{OH}^{-}+\mathrm{Quel}^{\mathrm{x}-} \rightarrow\left[\mathrm{Mg}^{2+} \cdot 6 \mathrm{H}_{2} \mathrm{O}^{2+}{ }_{(\mathrm{aq})}+\right. \\
& 2 \mathrm{OH}^{-} \mathrm{Quel}^{\mathrm{x}-} \rightarrow\left[\mathrm{Mg}^{2+} \cdot \text { Quel }^{\mathrm{x}-}\right]^{2-\mathrm{x}}{ }_{\text {(aq) }}+2 \mathrm{OH}^{-}
\end{aligned}
$$

ii) Os íons Quel ${ }^{\mathrm{x}-}$ são adsorvidos na superfície da magnésia, conforme a equação:
$\mathrm{MgOH}^{+}{ }_{\text {(superfíice) }}+\mathrm{OH}_{(\text {aq) }}^{-}+\mathrm{Quel}^{\mathrm{x}-}{ }_{(\mathrm{aq})} \rightarrow$
$\left[\mathrm{MgOH}^{+} \text {.Quel }{ }^{\mathrm{x}}\right]_{\text {superficie }}+\mathrm{OH}_{(\text {aq) }}^{-}$

Dessa forma, ou um ou outro fenômeno prevalecerá, dependendo da constante de estabilidade do quelante e da diminuição de energia gerada pela adsorção dos íons Quel ${ }^{\mathrm{x}}$ na superfície das partículas. A estabilidade do complexo depende do número de hidrogênios ionizáveis e da carga do complexo. As constantes de estabilidade dos possíveis complexos Mg-quelantes formados neste trabalho são apresentadas na Tabela I.

Tabela I - Constantes de estabilidade química dos complexos de magnésio [15].

[Table I - Chemical stability constants for the magnesium complexes [15].]

\begin{tabular}{ccc}
\hline & pKa & Ka \\
\hline EDTA $^{4-}$ & 8,69 & $2,04 \times 10^{-9}$ \\
$\mathrm{Cit}^{3-}$ & 3,20 & $6,31 \times 10^{-4}$ \\
$\mathrm{AT}^{2-}$ & 1,36 & $4,37 \times 10^{-2}$ \\
\hline
\end{tabular}

Além disso, a adsorção do quelante na superfície da magnésia pode ser investigada pela queda no potencial zeta das partículas de $\mathrm{MgO}$ na presença de cada aditivo. $\mathrm{O}$ aditivo que apresentar maior redução do potencial zeta pode indicar uma melhor adsorção. Entretanto, cabe ressaltar que a correspondência entre a redução do potencial zeta e o aumento da adsorção é válida quando a molécula de adsorvente possuir grupamentos negativos que interagem diretamente na superfície da partícula, como é o caso das moléculas pequenas de quelantes testadas. Por outro lado, moléculas poliméricas como dispersantes, por exemplo, possuem grupos laterais negativos os quais diminuem o potencial zeta, mas não são ancorados na superfície da magnésia. Dessa forma, o sistema tenderá a efetuar o que for mais estável energeticamente: formação de complexo ou adsorção na superfície do $\mathrm{MgO}$, dependendo das constantes de estabilidade do complexo, apresentadas na Tabela I e da afinidade do íons Quel ${ }^{\mathrm{x}-}$ pela superfície da magnésia, inferida pela redução da carga superficial da magnésia. Caso ocorresse apenas a formação de quelato, um favorecimento da hidratação da magnésia seria observado. A estabilização dos íons $\mathrm{Mg}^{2+}$ ocorreria pela formação de ambos os complexos: aquocomplexo $\mathrm{H}_{2} \mathrm{O}-\mathrm{Mg}$, em um processo conhecido por solvatação, ou do quelato $\mathrm{Mg}$-Quel, conhecido por quelação. Na ausência de quelantes apenas a solvatação é possível. Como maior quantidade de íons $\mathrm{Mg}^{2+}$ são desprendidos da estrutura cristalina do $\mathrm{MgO}$ na presença de quelantes (sejam eles complexados pela água ou pelo quelante), maior a dissolução da magnésia e portanto mais fácil a saturação da solução por íons $\mathrm{Mg}^{2+}$ e a conseqüente precipitação de hidróxido. Acredita-se que a utilização de acetato de magnésio em soluções de magnésia comporta-se 
como agente hidratante segundo esse mecanismo [8]. Por outro lado, se apenas a adsorção ocorresse, uma redução na reação de hidratação da magnésia seria esperado, pois essa adsorção dificultaria a aproximação dos íons $\mathrm{OH}^{-}$na superfície da magnésia, diminuindo sua dissolução (menor desprendimento de $\mathrm{Mg}^{2+}$ da estrutura cristalina para a suspensão) e a quantidade de hidróxido formada. Como ambos os fenômenos ocorrem simultaneamente (adsorção e quelação), deve-se maximizar a adsorção e reduzir a quelação para reduzir a hidratação do $\mathrm{MgO}$. Isso pode ser conseguido utilizando-se quelantes com elevada afinidade à adsorção e baixa estabilidade.

Conforme mostra a Fig. 4 e a Tabela I, o EDTA é o aditivo que produz o quelato mais estável e o que menos reduz o potencial zeta inicial da magnésia, sugerindo uma baixa adsorção em sua superfície e uma elevada quelação. A formação desse complexo facilita a dissolução, ou seja, acentua a queda do potencial zeta associado à dissolução da magnésia, podendo até atuar a favor da reação de hidratação. Após a dissolução ocorre um período indutivo, correspondente ao início da formação do $\mathrm{Mg}(\mathrm{OH})_{2}$ e à estabilização de $\zeta$, seguido pela continuidade da reação, ou seja, reprotonação da magnésia e o conseqüente aumento de $\zeta$.

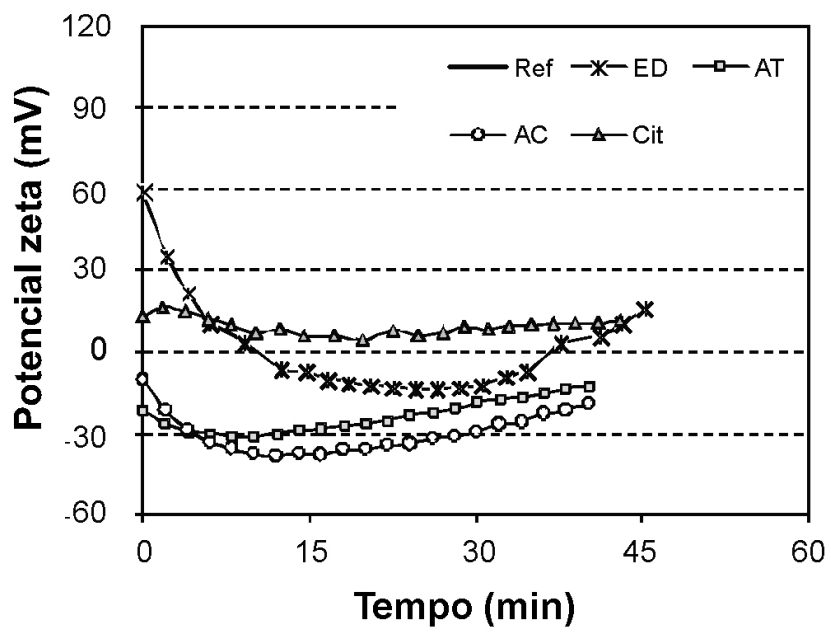

Figura 4: Potencial zeta em função do tempo para suspensões de sínter de magnésia $(12,5 \%$ p) na presença de diferentes quelantes. [Figure 4: Zeta potential with time for magnesia suspensions (12 wt\%) containing different quelants agents.]

Os aditivos que apresentaram a maior adsorção inicial na superfície da magnésia foram o ácido cítrico e o ácido tartárico, pois o $\zeta_{\mathrm{i}}$ tornou-se mais negativo devido a predominância das cargas negativas dos quelantes. Na Tabela I observa-se que as constantes de estabilidades dos complexos são próximas apesar do complexo com ácido tartárico ser menos estável, podendo justificar seu menor $\zeta_{i}$, em relação aquele na presença do ácido cítrico. Entretanto, mesmo com uma forte adsorção inicial, ocorre um processo de dissolução e reprotonação para ambos os casos (redução e recuperação de $\zeta$ ). Em contrapartida, o citrato de sódio não apresenta tal adsorção, mas o potencial zeta se mantém praticamente constante com o passar do tempo, sugerindo menor dissolução e reprotonação da magnésia nas etapas seguintes, podendo atuar positivamente contra a hidratação.

\section{Aspectos mecânicos e físicos associados à hidratação}

Para estudar os efeitos mecânicos gerados devido à hidratação da magnésia, iniciou-se a análise da hidratação da magnésia em suspensões mais concentradas, com e sem a presença de cimento de aluminato de cálcio.

Estudo de suspensões concentradas na ausência de CAC (Cimento de Aluminato de Cálcio)

As medidas de grau de hidratação apresentadas na Fig. 5 indicaram que há proporcionalidade entre a quantidade de hidróxido formada e a expansão gerada na amostra para três casos: a referência, o ácido tartárico e o ácido cítrico, enquanto nas extremidades do gráfico, o Cit, e o EDTA, apresentaram comportamentos distintos e opostos.

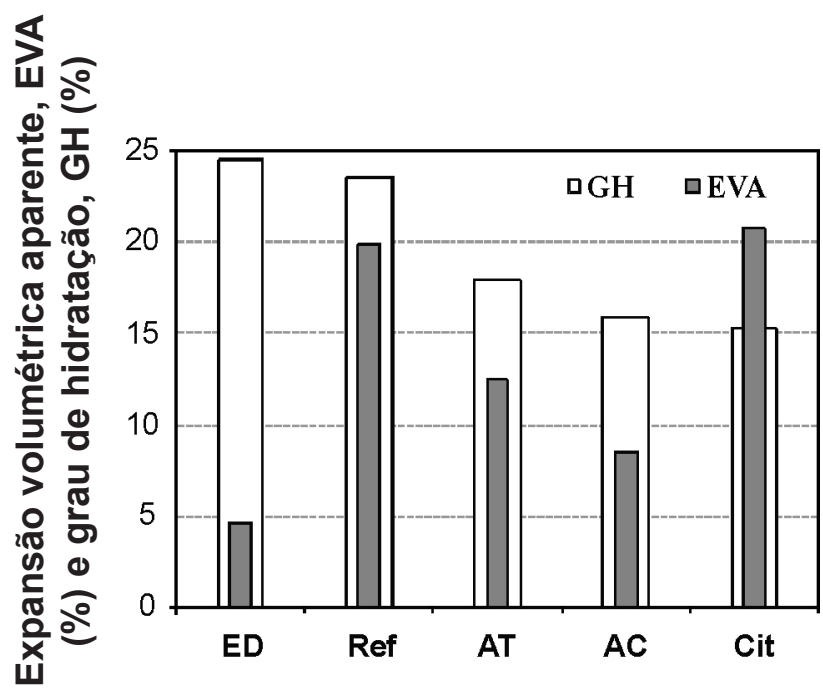

Figura 5: Grau de hidratação e expansão volumétrica aparente de amostras de magnésia sem CAC em função da presença de $0,3 \%$ p de diferentes quelantes após 7 dias a $50{ }^{\circ} \mathrm{C}$.

[Figure 5: Hydration degree and apparent volumetric expansion of $\mathrm{MgO}$ samples without CAC containing $3 \mathrm{wt} \%$ of different chelants after 7 days at $50^{\circ} \mathrm{C}$.]

O EDTA proporcionou o maior grau de hidratação e a menor expansão, enquanto o citrato de sódio se apresentou como o melhor inibidor da hidratação, mas em contrapartida apresentou a maior expansão. Assim, a formação da menor quantidade de hidróxido resultou na maior expansão da amostra, enquanto uma maior formação de hidróxido na presença de EDTA resultou no menor valor de expansão medida. Conforme mostrado anteriormente, o EDTA pode complexar os íons $\mathrm{Mg}^{2+}$ mais eficientemente, adsorvendo-se em menor quantidade na superfície da magnésia e por isso seu grau de hidratação é maior. Os outros aditivos reduzem 
de forma similar o grau de hidratação, indicando que não só a elevada adsorção na superfície da partícula (caso do AC e AT), mas também a adsorção de forma mais eficiente que dificulte as etapas posteriores de dissolução e reprotonação (caso do Cit) é capaz de evitar a reação. As fotografias apresentadas na Fig. 6 indicam que na amostra de citrato de sódio ocorreu segregação, impermeabilizando a superfície da amostra. Assim, durante a secagem, a saída de água se limita a abertura lateral do molde concentrando toda a tensão de crescimento do hidróxido neste local, que acaba trincando. A partir da formação dessa trinca, toda a expansão gerada se concentra nela, que aumenta de tamanho e leva a medida de EVA a valores muito altos, como os apresentados na Fig. 5. Analogamente, a amostra preparada na presença de EDTA não gera trincas e é capaz de acomodar o hidróxido sem que a tensão gerada pelo crescimento de seus cristais danifique a estrutura. Esse fator não é bem compreendido e para afirmar sua atuação são necessários ensaios complementares. Entretanto, propõem-se que o hábito cristalino da magnésia produzida nessas suspensões seja diferente, semelhante ao que Fillipou et al. sugere para a hidratação da magnésia na presença de acetato. Estes autores verificaram que o acetato de magnésio atua como agente hidratante para a magnésia, devido a formação de um complexo estável (Acetato-Mg) facilitando a dissolução da magnésia e conseqüentemente sua hidratação. O mesmo trabalho ainda constatou por microscopia eletrônica de varredura que o hidróxido formado nessas soluções cresce de forma homogênea, diferentemente da magnésia hidratada em água pura, onde a brucita cresce

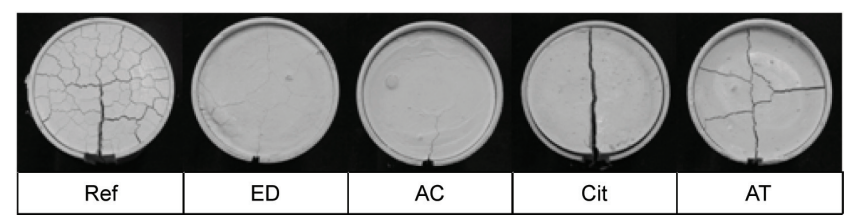

Figura 6: Fotografia das amostras de sínter de magnésia sem CAC na presença de diversos aditivos após 7 dias de cura.

[Figure 6: $\mathrm{MgO}$ samples without CAC containing $0.3 \mathrm{wt} \%$ of different chelants after 7 days at $50{ }^{\circ} \mathrm{C}$.]

de forma heterogênea [8].

\section{Estudo de suspensões concentradas na presença de CAC}

Uma vez que a aplicação da magnésia se destina principalmente a concretos refratários, dado as suas singulares vantagens, neste trabalho também foram analisadas suspensões na presença de cimento de aluminato de cálcio (CAC). A adição de cimento às suspensões torna o sistema mais complexo, já que envolve a ocorrência de duas reações de hidratação simultâneas e concorrentes: da magnésia formando hidróxido de magnésio e do cimento para formar hidratos de aluminato de cálcio. As curvas de perfil de secagem (Fig. 7) mostram que após um dia de cura ambos os produtos das reações foram formados: hidratos de CAC que se decompõem entre 150 e $350{ }^{\circ} \mathrm{C}$ [16] e hidróxido de magnésio por volta de $350-400{ }^{\circ} \mathrm{C}$ [17].
Ao aumentar o tempo de cura para 5 dias, a quantidade de hidratos praticamente não se altera, enquanto a quantidade de hidróxido aumenta abruptamente indicando que a reação de hidratação do cimento se completa em menor tempo quando comparada a hidratação da magnésia.

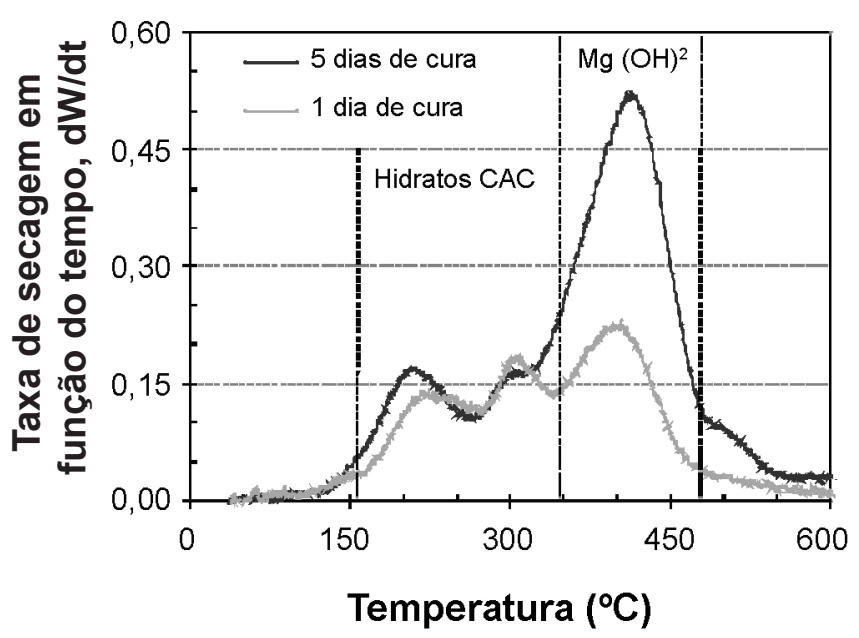

Figura 7: Perfil de secagem de amostras de sínter de magnésia (com $5 \%$ p de CAC) na ausência de quelantes, curadas por 1 e 5 dias a $50{ }^{\circ} \mathrm{C}$.

[Figure 7: Dry-out behavior of $\mathrm{MgO}$ samples (5 wt\% content of $\mathrm{CAC}$ ) without chelant, hydrated for 1 and 5 days at $\left.50^{\circ} \mathrm{C}.\right]$

Entretanto, na presença de CAC, ao contrário do verificado na sua ausência, ocorreu uma proporcionalidade entre a quantidade de hidróxido formada e a expansão gerada (Fig. 8). Neste caso, provavelmente como a formação de hidratos de CAC ocorre anteriormente à precipitação do hidróxido, estes devem ocupar os vazios disponíveis na estrutura.

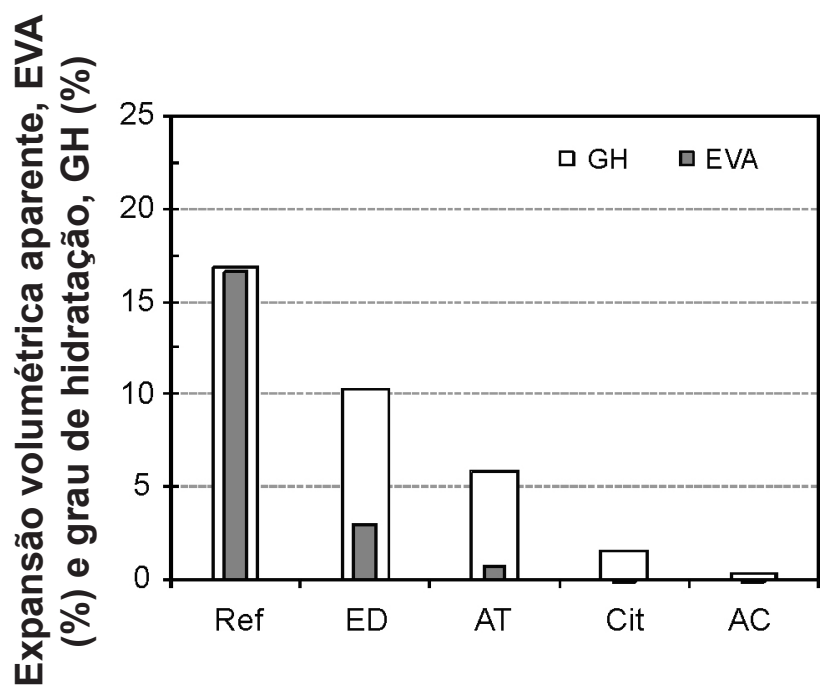

Figura 8: Grau de hidratação e expansão volumétrica aparente de amostras de sínter de magnésia contendo 5\%p de CAC e 0,3\%p de diferentes quelantes.

[Figure 8: Hydration degree and apparent volumetric expansion of $\mathrm{MgO}$ samples containing $5 \mathrm{wt} \% \mathrm{CAC}$ and $0.3 \mathrm{wt} \%$ of different chelants.] 


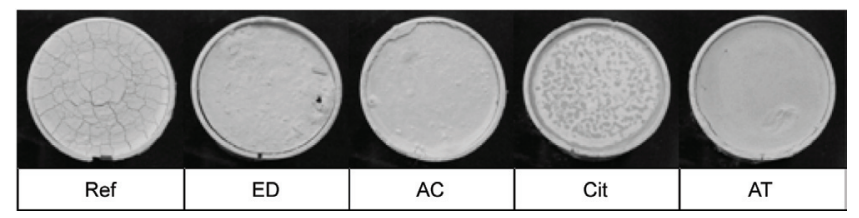

Figura 9: Fotografia das amostras de sínter de magnésia com CAC na presença de diversos aditivos após 7 dias de cura.

[Figure 9: $\mathrm{MgO}$ samples with $5 \mathrm{wt} \% \mathrm{CAC}$ containing $0.3 \mathrm{wt} \%$ of different chelants, after 7 days at $50^{\circ} \mathrm{C}$.]

Dessa forma, à medida que mais hidróxido é formado, maior a tensão gerada na estrutura e maior a expansão. Conforme mostrado na Fig. 8, a adição de cimento nas amostras reduziu o grau de hidratação da magnésia e principalmente os efeitos por ela gerados, anulando a expansão para três dos quatro quelantes testados. A redução do grau de hidratação pode ser atribuída à redução da quantidade de água disponível para a hidratação da magnésia e a redução na expansão à maior resistência mecânica da amostra, capaz de suportar maiores níveis de hidratação sem causar o trincamento da amostra (Fig. 9).

Neste caso, também é possível observar que o EDTA não atuou como agente hidratante, ou seja, facilitador da hidratação, como no caso sem cimento e que apesar de ter reduzido o grau de hidratação em relação a referência, apresentou uma expansão associada a esta. Esse fato pode ser associado a formação de um complexo ainda mais estável que o Mg-EDTA, o Ca-EDTA, cujo pKa é 10,54 [15]. Assim, o EDTA complexaria os íons $\mathrm{Ca}^{2+}$ provenientes do CAC e por isso perde sua função de complexante do Mg. Portanto, nesse caso, a única contribuição que seria observada seria a baixa adsorção na superfície da magnésia que reduziria um pouco a sua hidratação.

\section{CONCLUSÕES}

A reação de hidratação da magnésia foi estudada considerando-se seus aspectos químicos e físicos, na ausência e na presença de quelantes que podem atuar como aditivos anti-hidratação. Além disso, para estudar os aspectos físicos, amostras com e sem CAC foram preparadas a fim de aproximar o sistema de sua potencial aplicação, os concretos refratários. A presença do cimento de aluminato de cálcio afeta diretamente a atuação de quelantes sobre a hidratação da magnésia reduzindo tanto o seu grau de hidratação como os efeitos gerados por ela. Os aspectos químicos foram avaliados em suspensões diluídas (12,5\%p) de sínter de magnésia com uso das técnicas de potencial zeta, condutividade, $\mathrm{pH}$ e temperatura, concluindo-se que sob essas condições, a hidratação da magnésia estudada (sínter de magnésia) segue o princípio de dissolução/precipitação em sucessivos ciclos, conforme o ciclo de Le Chatelier. A presença de aditivos afeta significativamente a interação água/magnésia, não somente a etapa inicial de protonação da magnésia pela adsorção em sua superfície, mas também nas etapas posteriores de dissolução e reprotonação. Os aspectos físicos foram estudados em suspensões mais concentradas, (67,7\%p) de sínter de magnésia e não foi verificada total proporcionalidade entre a quantidade de hidróxido formado e a expansão gerada na amostra, quando não houve adição de ligante às suspensões. Na presença do quelante EDTA foi verificado maior grau de hidratação e menor expansão, enquanto na presença de citrato de sódio, um comportamento inverso foi detectado. Tal comportamento foi atribuído a presença de trincas na amostras de Cit e a um efeito ainda desconhecido para amostras com EDTA, mas que pode estar relacionado ao hábito cristalino do hidróxido formado. $\mathrm{Na}$ presença de cimento, ao contrário, ocorre proporcionalidade entre a quantidade de hidróxido formado e a expansão gerada. A formação de hidratos de cimento ocorre anteriormente à precipitação do hidróxido ocupando os vazios disponíveis na estrutura e à medida que mais hidróxido é formado, maior a tensão gerada na estrutura e maior a expansão. $\mathrm{O}$ uso dos quelantes Cit e $\mathrm{AC}$ reduziram em quase 3 vezes a quantidade de hidróxido formada em relação a ausência de aditivos e anularam a expansão em suspensões de sínter de magnésia com 5\%p de CAC.

\section{AGRADECIMENTOS}

À CAPES e a Magnesita S.A. pelo suporte e apoio financeiro.

\section{REFERÊNCIAS}

[1] R. Salomão, L. R. M. Bittencourt, V. C. Pandolfelli, A novel approach for magnésia hydration assessment in refractory castables, Ceram. Int. 33, 5 (2007) 803-810.

[2] N. Zhou, S. Hu, S. Zhang, Advances in modern refractory castables, China's Refractories 13, 2 (2004) 3-12.

[3] T. A. Bier, C. Parr, C. Revais, M. Vialle, Spinel forming castables: physical and chemical mechanisms during drying, Refractories Appl. 5, 4 (2000) 3-4.

[4] B. Heidberg, T. Bredow, K. Littmann, K. Jug, Ceramic hydration with expansion, The structure and reaction of water layers on magnesium oxide, A cyclic cluster study, Mater. Sci.-Poland 23, 2 (2005) 501-508.

[5] V. S. S. Birchal, S. D. F. Rocha, V. S. T. Ciminelli, The effect of magnesite calcinations conditions on magnesia hydration, Minerals Eng. 13, 14-15 (2000) 1629-1633.

[6] A. Kitamura, K. Onizuka, K. Tanaka, Hydration characteristics of magnesia, Taikabutsu Overseas 16, 3 (1995) 3-11.

[7] H. Jost, M. Braun, C. Carius, The role of reactivity in syntheses and the properties of magnesium oxide, Solid State Ionics 101-103 (1997) 221-228.

[8] D. Filippou, N. Katiforis, N. Papassiopi, K. Dam, On the kinetics of magnesia hydration in magnesium acetate solutions, J. Chem. Technol. Biotechnol. 74 (1999) 322328.

[9] O. Fruhwirth, G. W. Herzog, I. Hollerer, A. Rachetti, Dissolution and hydration kinetics of $\mathrm{MgO}$, Surface Technol. 24 (1985) 301-317.

[10] S. D. F. Rocha, M. B. Mansur, V. S. T. Ciminelli, Kinetics 
and mechanistic analysis of caustic magnesia hydration, $\mathrm{J}$. Chem. Technol. Biotechnol. 79, 8 (2004) 816-821.

[11] G. Huazhi, J. Ouyang, H. Wang, W. Zhang, J. Sun, C. $\mathrm{Lu}, \mathrm{Y}$. Hong, The hydration resistance of $\mathrm{CaO}-\mathrm{MgO}$ clinker treated by $\mathrm{H}_{2} \mathrm{C}_{2} \mathrm{O}_{4}$ solution, in UNITECR 2003, Osaka, Japan (2003).

[12] S. Lu, G. Chen, J. Cheng, Improved hydration resistance of synthesized magnesia-calcia clinker by surface modification, J. Am. Ceram. Soc. 87, 12 (2004) 2164-2167. [13] L. F. Amaral, R. Salomão, E. Frollini, V. C. Pandolfelli, Mecanismos de hidratação do óxido de magnésio, Cerâmica 53, 328 (2007) 368-372.

[14] I. R. Oliveira, A. R. Studart, R. G. Pileggi, V. C.
Pandolfelli, Dispersão e empacotamento de partículas, Fazendo Arte Editorial, SP (2000).

[15] K. B. Yatsimirskii, V. P. Vasil'ev, Instability constants of complex compounds, New York: Consultants Bureau Enterprises (1960) 214.

[16] T. D. Robson, Aluminous cement in refractory castables, in The Chemistry of Cements, Vol. 2, Academic Press, EUA (1964).

[17] E. Van Der Merwe, C. Strydom, Quantitative thermogravimetric analysis of binary mixtures: magnesium hydroxide and magnesium acetate, J. Thermal Analysis Calorimetry 76, 8 (2004) 149-156.

(Rec. 27/03/2008, Ac. 05/12/2008) 